\title{
Botox, Migraine, and the American Academy of Neurology: An Antidote to Anecdote
}

\author{
Mark Jackson, RPh, BScPhm, BComm, and John P. Barbuto, MD
}

$\mathrm{W}$ hat do we learn when a popular treatment is found to be ineffective? What do we carry away so that we may be more insightful the next time? These are important questions brought into focus as the American Academy of Neurology published its position statement in May 2008 advocating that botulinum toxin (Botox), in spite of its popularity in the headache treatment realm, "is probably ineffective in episodic migraine and chronic tension-type headache."

For many reasons, treatments may be seemingly effective, while they are not actually effective. A treatment may be seemingly effective for a condition-while not actually effectivewhen it treats another condition that is routinely coexistent. For example, an infection may be improved, for a while, with an anti-inflammatory agent. Or, a treatment may be only seemingly effective if it improves a patient's attitude and thus improves hope and optimism, both of which tend to ameliorate symptoms - part of the placebo effect. Further, a treatment may be only seemingly effective if use of the treatment produces some psychological or social advantage, which is desired in conjunction with presence of the illness. For example, endless modality therapy (e.g., massage, heat, and other "hands-on" physical-type therapies) may be desired by an accident claimant because the service "authorizes" continuation of the accident claim litigation, while the therapies themselves may show no evidence of resolving the claimed syndrome. The list of such behaviors is relatively extensive. Health care is a complex biopsychosocial process. But, because psychological and social explanations for behavior in health care are often unwelcome, it is commonly convenient to presume that claims of treatment effectiveness must, of necessity, reveal pathophysiologic relevance. Yet, sometimes science eventually gets around to confronting convenience.

In the case of botulinum toxin, a specific theory of effectiveness in treating migraine has been lacking. Schulte-Mattler and Leinisch point out that botulinum toxin blocks the release of acetylcholine and also reduces release of neuropeptides involved in pain perception, but then go on to say, "The implications of these observations are not clear." They further observe that, in randomized, placebo-controlled studies, "botulinum toxin and placebo injections have been equally effective."' Skeptics have quietly argued (though minimally in the literature) that perhaps desired cosmetic effects or stress-induced tension are really what was being addressed under the auspices of claimed migraine effectiveness. So, how can we know when a seemingly effective therapy is really serving some alternative mechanism or dynamic? The answer, recurrently, is the same: the treatment hypothesis fails solid pathophysiologic scrutiny.
A century ago, in the early era of understanding microbial infection, Robert Koch defined the subsequently famous "Koch's Postulates": a series of 4 requirements, which must be met to confirm that an organism was truly a cause of infection and not merely a bystander. ${ }^{3}$ By these efforts, he advocated that we prove a pathophysiologic causal relationship between exposure to an infectious agent and development of disease. Likewise, in the effort to separate true treatment effectiveness from pseudoeffectiveness, we are wise to move beyond anecdotal claim. We are wise to seek objective evidence of a pathophysiologic chain that logically explains treatment effectiveness.

Historically, many theories have been considered regarding migraine etiology and treatment, from supernatural causes to be treated through trepanation (boring or scraping a hole in the skull to allow evil spirits to escape) to the Hippocratic and Galenic belief in vapors rising from the stomach to the brain. Vascular theories on the etiology of migraine were originally discussed in the 17th century, with neurological/neurogenic theories being developed in the 19th century. In the 20th century, allergic underpinnings for migraine were briefly investigated in the 1920s, and migraine as a psychosomatic disorder was considered in the 1940s and 1950s. Most modern research on the pathophysiology of migraine continues to involve one or both of the vascular and neurogenic theories of migraine.,5

In the late 1990s and early 2000s, reports of the use of botulinum toxin type A for the treatment of headache, including migraine, began to appear in the literature. ${ }^{6-8}$ These early reports were typically the result of nonrandomized, open-label designs and suggested significant effectiveness in reducing migraine frequency and severity. Subsequent studies have been less impressive, with many failing to meet their primary endpoints of migraine frequency, ${ }^{9-11}$ number of days with migraine, ${ }^{10}$ number of total single doses to treat a migraine attack, ${ }^{10}$ and severity. ${ }^{11}$

In this issue of JMCP, Mitchell et al. have provided a glimpse of a managed care organization's real-life experience in the world of coverage for botulinum toxin (primarily type A) for refractory migraine. ${ }^{12}$ Although the drug was not approved by the U.S. Food and Drug Administration (FDA) for this indication, the use of the botulinum toxin as a migraine treatment sounded promising based on the literature available at the time of the health plan's decision to cover the drug in 2003. Using a prior authorization policy, the health plan restricted treatment of migraine with botulinum toxin to patients who (1) failed at least 3 different acute treatment therapy classes, (2) failed at least 4 different preventive medication classes, and (3) received consultation from a neurologist. The authors report that, despite 
some favorable patient-reported improvements (headache frequency, severity, etc.), analyses of administrative claims data documented increases in the use of acute migraine-related medications and in overall pharmacy and medical costs. In other words, the treatment, which was supposed to be effective, was actually associated with increased costs of coexisting treatments.

Looking in the rearview mirror, Mitchell et al.'s results are hardly surprising since their findings appear to be consistent with the literature published subsequent to their coverage decision in 2003. Since 2006, several literature reviews and editorials have called into question the use of botulinum toxin type A for the prophylaxis of migraine. Evers and Olesen,,${ }^{13}$ Ateş, ${ }^{14}$ Gupta, ${ }^{15}$ Pakalnis and Couch, ${ }^{16}$ and Roach ${ }^{17}$ have argued that current evidence does not support the use of botulinum toxin type A injections for migraine prophylaxis. Some have noted that some patient subpopulations may benefit from such treatment for some headache types, but identifying these patients will be difficult. ${ }^{13,16,17}$ Finally, and perhaps most notably, was the previously mentioned May 2008 recommendation of the American Academy of Neurology against the use of botulinum neurotoxin in the treatment of episodic migraine and chronic tension-type headache. ${ }^{1}$

Given the evidence, one would think that the end must be near for botulinum toxin type $\mathrm{A}$ in the treatment of migraine. This is unlikely to be the case. In a January 2008 editorial, Roach noted that "the fact that [botulinum neurotoxin] is lucrative and easy to administer does little to foster much needed objectivity and skepticism." ${ }^{17}$ A simple Google search for "Botox migraine" yields many hits for Web sites, such as www. nationalreviewofmedicine.com, ${ }^{18}$ www.relieve-migraineheadache.com, ${ }^{19}$ www.headache-help.org, ${ }^{20}$ and www.migraines .org, ${ }^{21}$ in addition to several sites for medical skincare and cosmetic medicine promoting the drug for migraine. Nowhere in the first 5 pages of the hits returned in the Google search does a site appear that is negative to botulinum toxin for migraine. The Wikipedia page for botulinum toxin identifies migraine as a use for the drug before it mentions FDA-approved indications, such as cervical dystonia, blepharospasm, or hyperhydrosis.22 Patients are clearly bombarded with a message that is not supported by the bulk of the current evidence.

All too often, when a popular treatment is found to be ineffective, we carry away nothing, we learn nothing. All too often we say, "Well, that didn't work," and think no further. This is a very significant error. In the annals of medicine (and particularly in the annals of folk remedies), there are myriad examples of failed therapeutic approaches that were vigorously advocated by those who provided them (typically with willing anecdotal reports by some consumers). Over the centuries, all manner of invocations, electrical therapies, pressures, punctures, ointments, tinctures, magnets, heats, lights, and other treatments have been offered, advocated, consumed, and later discarded as useless (in noneconomic terms). Even though these myriad examples are different, they are recurrently similar. Medical fads are recurrently connected by a similar paradigm: (1) an acceptable (though often unmeasurable) hypothesis, (2) a utilitarian opportunity that eagerly propagates the hypothesis, (3) a failure to consider alternate explanations for "effectiveness," (4) a slow intrusion of scientific scrutiny into a realm of preferred belief, (5) an eventual (after years) debunking of the original hypothesis, (6) a slow discarding of the therapy, and (7) a prompt conjuring of a new opportunistic hypothesis with little or no effort to learn from the prior "adventure." Notably, in fads, the "acceptable hypothesis" routinely proceeds as presumed mechanism: mechanisms asserted to be present but typically with little or nothing that can be objectively measured in the patient.

We must ultimately decide whether it is in the best interest of patients to provide truly effective therapy or to provide demanded utilitarian services. If our goal is the former, then we must seek to learn from popular therapies, which are later shown to be ineffective, in spite of their popularity and vigorous adherents. We must ask what allowed us to become caught up in providing treatments that were serving something other than the therapeutic target. We must ask if our seemingly effective service is treating what we think it is or something else. And, the key to this pursuit is, recurrently, a candid examination of pathophysiology.

Pathophysiology is the linkage between cause and symptoms. It is also the linkage between treatment and true effectiveness. There are historically well-recognized pathophysiologies of many types, including: trauma, tumor, inflammation, infection, toxin degeneration, genetic disorder, and so forth. These classic ones have now been elaborated into numerous mechanisms of subtle biochemical and structural disorder. Migraine is such an illness. It is believed to stem from (and proceed through) complex mechanisms of neurochemical disorder. Therefore, discussions of pathophysiology have become very complex. Nonetheless, we should expect to see some logical relationship between the specific mechanisms of the illness and the specific effects of the treatment.

To measure true treatment effectiveness, we might strive to measure something other than verbal claims. In migraine, this endeavor is difficult. Many patients, particularly those with claims of chronic headaches, present recurrently to the doctor with words describing their asserted level of illness but without objective evidence of being ill. In fact, the patient may sit in the clinic reception area reading a magazine and chatting with friends and then report that their level of pain is 8 on a 0-to-10 scale. Those who treat migraine become used to such glaring disparities. However, familiarity does not excuse complacence. When the treatment of such a patient is said to be effective, we should be driven to wonder by what mechanism it is effective.

To be sure, we must not commit the error of hubris. We must not presume that we know all the answers, all the pathophysiologies, or all the possibilities. Within reason, we must be willing to examine serendipity: newly reported effective therapies that 
may reveal new pathophysiologic insights. We must be willing to let a new therapeutic hypothesis have its due consideration. However, this does not authorize relegating health care to nothing more than an economic adventure or an endless string of "snake oils." Patients and society depend upon us being willing to proceed with a true center on doing what is medically appropriate. Therefore, as we allow new ideas, we must continue to look for pathophysiologic reason.

Going forward, it might be that new information will exonerate the use of botulinum toxin in migraine. But, for the time being, it appears from recent literature and from the American Academy of Neurology position that this adventure has been promulgated by issues other than true pathophysiologic effectiveness for migraine or tension headache. And this understanding provides a focus for us to examine the important issue of learning from flawed medical adventures. It is not a fault to reasonably follow a hypothesis that is later disproven. It is a fault to learn nothing and to remain equally vulnerable the next time.

\section{Authors}

MARK JACKSON, RPh, BSCPhm, BComm, is Provider and Professional Services Liaison, Green Shield Canada, 8677 Anchor Dr., P.O. Box 1606, Windsor, Ontario N9A 6W1 Canada.

Tel.: 519.739.1133, ext. 6215; E-mail: Mark.jackson@greenshield

JOHN P. BARBUTO, MD, is Director, Outpatient Neurology, HealthSouth Rehabilitation Hospital, 8074 South 1300, East Sandy, UT 84094.Tel.: 801.565.6500; E-mail: doctorbarbuto@comcast.net

\section{REFERENCES}

1. Naumann M, So Y, Argoff CE, et al., for the Therapeutics and Technology Assessment Subcommittee of the American Academy of Neurology. Assessment: botulinum neurotoxin in the treatment of autonomic disorders and pain (an evidence-based review): report of the Therapeutics and Technology Assessment Subcommittee of the American Academy of Neurology. Neurology. 2008;70(19):1707-14.

2. Schulte-Mattler WJ, Leinisch E. Evidence based medicine on the use of botulinum toxin for headache disorders. J Neural Transm. 2008; 115(4):647-51.

3. Koch's postulates. Available at: http://en.wikipedia.org/wiki/ Koch\%27s_postulates. Accessed June 7, 2008.

4. Villalon CM, Cenurion D, Valdivia LF, de Vries P, Saxena PR. Migraine: pathophysiology, pharmacology, treatment, and future trends. Curr Vasc Pharmacol. 2003;1(1):71-84.
5. Pearce JMS. Historical aspects of migraine. J Neurol Neurosurg Psychiatry. 1986;49(10):1097-1103.

6. Binder WJ, Brin MF, Blitzer A, Schoenrock LD, Pogoda JM. Botulinum toxin type A (BOTOX) for treatment of migraine headaches: an open-label study. Otolaryngol Head Neck Surg. 2000;123(6):669-76.

7. Wheeler AH. Botulinum toxin A, adjunctive therapy for refractory headaches associated with pericranial muscle tension. Headache. 1998; 38(6):468-71.

8. Silberstein S, Mathew N, Saper J, Jenkins S. Botulinum toxin type A as a migraine preventive treatment. For the BOTOX Migraine Clinical Research Group. Headache. 2000;40(6):445-50.

9. Aurora SK, Gawel M, Brandes JL, Pokta S, VanDenburgh AM. Botulinum toxin type A prophylactic treatment of episodic migraine: a randomized, double-blind, placebo-controlled exploratory study. Headache. 2007; 47(4):486-99.

10. Evers S, Vollmer-Hasse J, Schwaag S, Rahmann A, Husstedt I-W, Frese A. Botulinum toxin A in the prophylactic treatment of migrainea randomized, double-blind, placebo-controlled study. Cephalalgia. 2004;24(10):838-43.

11. Cady R, Schreiber C. Botulinum toxin type A as migraine preventive treatment in patients previously failing oral prophylactic treatment due to compliance issues. Headache. 2008;48(6):900-13.

12. Mitchell MP, Schaecher K, Cannon HE, Speckman M. Humanistic, utilization and cost outcomes associated with the use of botulinum toxin for treatment of refractory migraine headaches in a managed care organization. J Manag Care Pharm. 2008;14(5):442-50.

13. Evers S, Olesen J. Botulinum toxin in headache treatment: the end of the road? Cephalalgia. 2006;26(7):769-71.

14. Ateș Y. Botulinum toxin for the treatment of headaches: a review of current practices and evidence-based data. Agri. 2006;18(3):5-11.

15. Gupta VK. Botulinum toxin-a treatment for migraine? A systematic review. Pain Med. 2006;7(5):386-94.

16. Pakalnis A, Couch J. Headache therapy with botulinum toxin-form over substance. Arch Neurol. 2008; 65(1):149-51.

17. Roach ES. Questioning botulinum toxin for headache-reality or illusion. Arch Neurol. 2008;65(1):151-52.

18. La Giorgia G. Botox shots pinpoint migraine culprits. Plastic surgeons, neuros team up for injection-guided surgery. National Rev Med. 2007; 4(7):1-3. Available at: www.nationalreviewofmedicine.com/issue/2007/ 04_15/4_advances_medicine02_7.html. Accessed May 21, 2008.

19. Anonymous. Is there a Botox migraines connection? Available at: www.relieve-migraine-headache.com/botox-migraines.html. Accessed May 21, 2008

20. Klapper JA. Botox \& migraine. Available at: www.headache-help.org/ Articles/Botox-and-Migraine.htm. Accessed May 21, 2008.

21. Anonymous. Botox for migraines. Available at: www.migraines.org/ treatment/probotox.htm. Accessed May 21, 2008

22. Anonymous. Botulinum toxin. Available at: http://en.wikipedia.org/ wiki/Botox. Accessed May 21, 2008. 